\title{
Possitive correlation between adipocyte fatty acid-binding protein and epicardial fat in patients with a family history of cardiovascular disesase
}

\author{
Eliska Sovova a , Milan Sova ${ }^{b}$, Jana Zapletalovac, David Stejskal ${ }^{d}$, Marketa Sovovae , Marketa Kaletovaa , Gabriela Svobodovad, \\ Irena Kuca ${ }^{f}$, Michal Janak', Milan Kaminek ${ }^{\mathrm{h}}$
}

Background. Adipocyte fatty acid-binding protein (A-FABP) is a promising link between metabolic syndrome and atherosclerosis. Epicardial fat (EPI) is an independent risk factor for cardiovascular disease (CVD).

Objective. The aim of this pilot study was to evaluate the correlation between EPI and A-FABP in asymptomatic patients with a family history of CVD.

Methods. 59 subjects ( 39 males) (median $=54$ years old) were enrolled in the study and their EPI thickness and A-FABP levels were assessed.

Results. EPI was found in 46 patients (77.9\%). There were positive correlations between EPI and A-FABP ( $r=0.336$; $P=0.010)$, age $(r=0.526 ; P<0.001)$, fibrinogen $(r=0.304 ; P=0.023)$ and systolic blood pressure $(r=0.279 ; P=0.034)$. A positive correlation was found between EPI and A-FABP in a subgroup of overweight and obese patients $(0.389 ; P=0.041$, $0.407 ; P=0.004)$ and in the subgroup of patients with excluded CVD $(r=0.368 ; P=0.006)$.

Conclusions. We found a positive correlation between EPI and A-FABP in a group of patients with a family history of CVD and in subgroups of overweight and obese patients.

Key words: Adipocyte fatty acid bindig protein, epicardial fat, risk of cardiovascular disease, echocardiography

Received: August 13, 2016; Accepted with revision: March 30, 2017; Available online: May 16, 2017 https://doi.org/10.5507/bp.2017.018

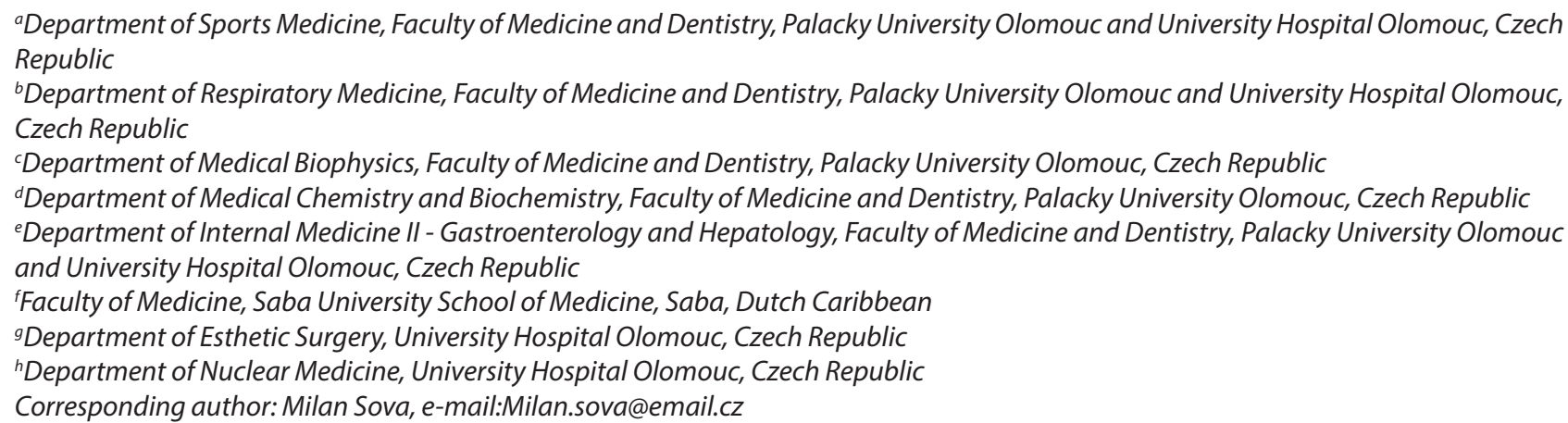

\section{INTRODUCTION}

Cardiovascular disease (CVD) is the most common cause of death in Europe and USA. There is solid evidence that visceral fat plays an essential role in the development of metabolic and cardiovascular diseases. Ectopic fat deposition has been implicated in the pathophysiology of diabetes, insulin resistance and obesity-related disorders ${ }^{1}$.

Epicardial fat (EPI) is a local deposition of visceral adipose tissue; its occurrence is connected with obesity, diabetes, arterial hypertension and other cardiovascular diseases, and malignant neoplasms ${ }^{1,2}$. EPI is correlated with various cardiovascular risk factors, independent of abdominal visceral adiposity, body mass index, hypertension and diabetes mellitus ${ }^{3}$. Two population studies showed that EPI is an independent risk predictor for cardiovascular disease $\mathrm{e}^{4,5}$. Adipose tissue is a metabolically active organ secreting adipocytokines and EPI has a considerable secretory activity (more mRNA, protein for IL-1B, IL-6 and TNF $\alpha$ (ref. ${ }^{1}$ ).
Adipocyte fatty acid-binding protein (A-FABP, also known as FABP4 or aP2) is one out of nine members of the family of fatty acid-binding proteins (FABPs) (ref. $\left.{ }^{6}\right)$. According to Hsu et al., the fasting level of A-FABP is positively correlated with metabolic syndrome diagnostic criteria ${ }^{7}$. A-FABP may be a promising link between metabolic syndrome and atherosclerosis ${ }^{8}$ and a new biomarker for predicting the development of type II diabetes mellitus ${ }^{9}$. In mouse models, a protective effect of A-FABP deficiency on the development of atherosclerosis was demonstrated ${ }^{10}$. Several studies reported a correlation between serum A-FABP levels and coronary artery disease $^{11,12}$, with CVD patients having significantly higher A-FABP levels. In a study on A-FABP in atherosclerotic plaques, Peeters et al. found that A-FABP levels correlated with unstable plaque characteristics and symptomatic lesions $^{13}$. Doi et al. reported that A-FABP levels in males under 65 years of age are significantly associated with coronary artery disease, independent of established risk factors ${ }^{14}$. Our team has been studying this biomarker for 
several years in patients with obstructive sleep apnea as well as in patients with increased cardiovascular risk ${ }^{15-16}$.

According to the available literature, only one study of correlation between A-FABP and epicardial fat has been published. In that study, Baessler at el. ${ }^{17}$ found a positive correlation between the amount of epicardial fat and A-FABP in a group of morbidly obese subjects.

The aim of our study was to evaluate the correlation between EPI and A-FABP in asymptomatic patients with family history of CVD, stratified according to BMI (normal, overweight, obese).

\section{SUBJECTS AND METHODS}

The study comprised 59 subjects (39 males) aged between 32 and 73 years (median $=54$ years), all asymptomatic first-degree relatives of patients with CVD - coronary heart disease (CHD) or stroke. Anthropometric and physical measurements - body weight, height, body mass index (BMI), casual blood pressure, and laboratory tests were performed.

Serum uric acid, creatinine, total cholesterol, high density lipoprotein (HDL) cholesterol, LDL cholesterol, triglycerides, insulin, glucose, C-reactive protein (CRP), apolipoprotein A (apo A), apolipoprotein B (apo B), lipoprotein(a) (Lp(a)), fibrinogen and glycated hemoglobin levels were analyzed in fresh serum obtained from venous blood collected after $12 \mathrm{~h}$ of fasting according to the manufacturer's instructions.

Measuring A-FABP levels: Venous blood was collected after $12 \mathrm{~h}$ of overnight fasting. Plasma levels were measured by enzyme-linked immunosorbent assay (BioVendor Laboratory Medicine Inc., Brno, Czech Republic) according to the manufacturer's instructions. To determine variability, intra- and inter-assay variance, human plasma was used with 3 different samples being assessed (CV intra-assay $<4.8 \%$, CV inter-assay $<10 \%$ ).

Laboratory analyses were blinded i.e. carried out without access to clinical data.

Echocardiography was performed using VIVID 7 GE Medical. Epicardial fat thickness was measured in the parasternal view (long and short axis) on the right ventricular free wall in diastole, using the mean of three consecutive beats $^{2}$, as a hypoechoic space between the epicardial surface and the parietal pericardium. If there was a difference between the measurement in long and short axis the result was taken to be the mean value of these two measurements.

Table 1. Basic characteristics and correlation coefficients with epicardial fat.

\begin{tabular}{lcc}
\hline $\mathrm{n}=59$ & Mean $\pm \mathrm{SD}$ & $P$ \\
\hline Age $($ years $)$ & $53.3 \pm 10.8$ & $\mathbf{0 . 5 2 6}^{*}$ \\
A-FABP $(\mu \mathrm{g} / \mathrm{L})$ & $25.8 \pm 12.8$ & $\mathbf{0 . 3 3 6}^{*}$ \\
Creatinine $(\mu \mathrm{mol} / \mathrm{L})$ & $80.2 \pm 3.9$ & 0.046 \\
Uric acid $(\mu \mathrm{mol} / \mathrm{L})$ & $346.4 \pm 93.3$ & -0.073 \\
CRP $(\mathrm{mg} / \mathrm{L})$ & $3.1 \pm 4.8$ & 0.120 \\
Total cholesterol $(\mathrm{mmol} / \mathrm{L})$ & $5.1 \pm 0.8$ & -0.157 \\
Triglycerides $(\mathrm{mmol} / \mathrm{L})$ & $1.6 \pm 0.8$ & 0.183 \\
HDL cholesterol $(\mathrm{mmol} / \mathrm{L})$ & $1.4 \pm 0.4$ & -0.105 \\
LDL cholesterol $(\mathrm{mmol} / \mathrm{L})$ & $3.1 \pm 0.7$ & -0.126 \\
Index.Ch/HDLc & $3.9 \pm 1.0$ & 0.088 \\
ApoA lipoprotein $(\mathrm{g} / \mathrm{L})$ & $1.5 \pm 0.3$ & -0.121 \\
ApoB lipoprotein $(\mathrm{g} / \mathrm{L})$ & $0.9 \pm 0.2$ & -0.033 \\
Glucose $(\mathrm{mmol} / \mathrm{L})$ & $5.4 \pm 1.4$ & 0.045 \\
Glycated Hb $\%$ ) & $4.0 \pm 1.0$ & 0.214 \\
Insulin $(\mathrm{mIU} / \mathrm{L})$ & $11.3 \pm 1.4$ & 0.124 \\
Fibrinogen $(\mathrm{g} / \mathrm{L})$ & $3.0 \pm 0.9$ & $\mathbf{0 . 3 0 4 *}$ \\
BP systolic mm Hg & $132.3 \pm 25.7$ & $\mathbf{0 . 2 7 9 *}$ \\
BP diastolic mm Hg & $82.2 \pm 12.0$ & 0.036 \\
BMI & $28.5 \pm 3.9$ & 0.085 \\
\hline
\end{tabular}

BP blood pressure, BMI body mass index * $\boldsymbol{P} \leq \mathbf{0 . 0 5}$

Table 2. Correlations (Spearman's) between epicardial fat and A-FABP depending on BMI.

\begin{tabular}{lccc}
\hline BMI & n & Correlations & $P$ \\
Normal & 10 & -0.100 & 0.783 \\
Overweight & 29 & 0.389 & 0.041 \\
Overweight plus obesity & 20 & 0.407 & 0.004 \\
\hline
\end{tabular}


The total CS was calculated using the Agatston method without the need for a contrast agent ${ }^{2}$. To identify calcified lesions, the usual threshold of 130 Hounsfield units was used. Patients were classified into categories with risks corresponding to the $\mathrm{CS}$ as follows: normal (0), minimum risk (1-10), mild risk (11-100), moderate risk (101-400) and high risk (above 400). CT scans to determine the CS were performed with the Siemens Biograph-16 16-slice PET/CT scanner; ECG gating was used to obtain images at the same phase of the cardiac cycle (end-diastole) (reconstruction of 3-mm slices).

SPECT was performed with the Siemens e.cam dualdetector scintillation camera equipped with low-energy high-resolution parallel-hole collimators, using 8-frame gating, $180^{\circ}$ rotation angle, a total of 64 projections in a $64 \times 64$ matrix from $45^{\circ}$ right anterior oblique projection to $45^{\circ}$ left posterior oblique projection.

Coronarography was performed in patients with patological findings on SPECT with the Phillips Allura Xper FD 10 according to common protocol.

All participants gave informed consent to the study approved by the Ethics Committee of the Faculty of Medicine and Dentistry, Palacky University Olomouc.

\section{Statistical analysis}

SPSS software version 15.0 (SPSS Inc., Chicago, USA) was used for statistical analysis. Spearman's correlation analysis was carried out to evaluate the relationship between EPI and A-FABP and other baseline variables. The normality of distribution was checked by the Shapiro-Wilk test. $\mathrm{P}<0.05$ was considered statistically significant.

\section{RESULTS}

Basic characteristics (arithmetic mean $\pm \mathrm{SD}$, 1st quartile/median/3rd quartile) of the analyzed data set are shown in Table 1. Of the total 59 participants, 35 patients (59.3\%) were pharmacologically treated for arterial hypertension, 5 patients (8.5\%) had type 2 diabetes mellitus, 16 patients $(27.1 \%)$ were smokers, and 1 patient $(1.7 \%)$ was an ex-smoker. Overweight obese were noted in 29 (49.15\%) and 20 (33.89\%) patients, respectively. A mild calcium score was present in $13(22.0 \%)$ patients, a moderate calcium score in $6(10.2 \%)$, and a severe calcium score in $2(3.4 \%) .6$ patients $(10.16 \%)$ had a pathological finding on SPECT, ischemic heart disease was found in $4(6.8 \%)$ patients (by coronarography).

EPI was present in 46 patients $(77.9 \%)$ with a mean value of $2.91 \mathrm{~mm}$. Ten patients had EPI $>5 \mathrm{~mm}$.

Spearman correlation analysis showed a significant positive correlation between EPI and A-FABP ( $\mathrm{r}=0.336$; $P=0.010)$ (see Fig 1$)$, and age $(\mathrm{r}=0.526 ; P<0.001)$, fibrinogen $(\mathrm{r}=0.304 ; P=0.023)$ and systolic blood pressure $(\mathrm{r}=0.279 ; P=0.034)$ (see Table 1$)$.

The correlation between EPI and A-FABP in patients with normal BMI, in overweight patients, and in obese patients is shown in Table 2 .

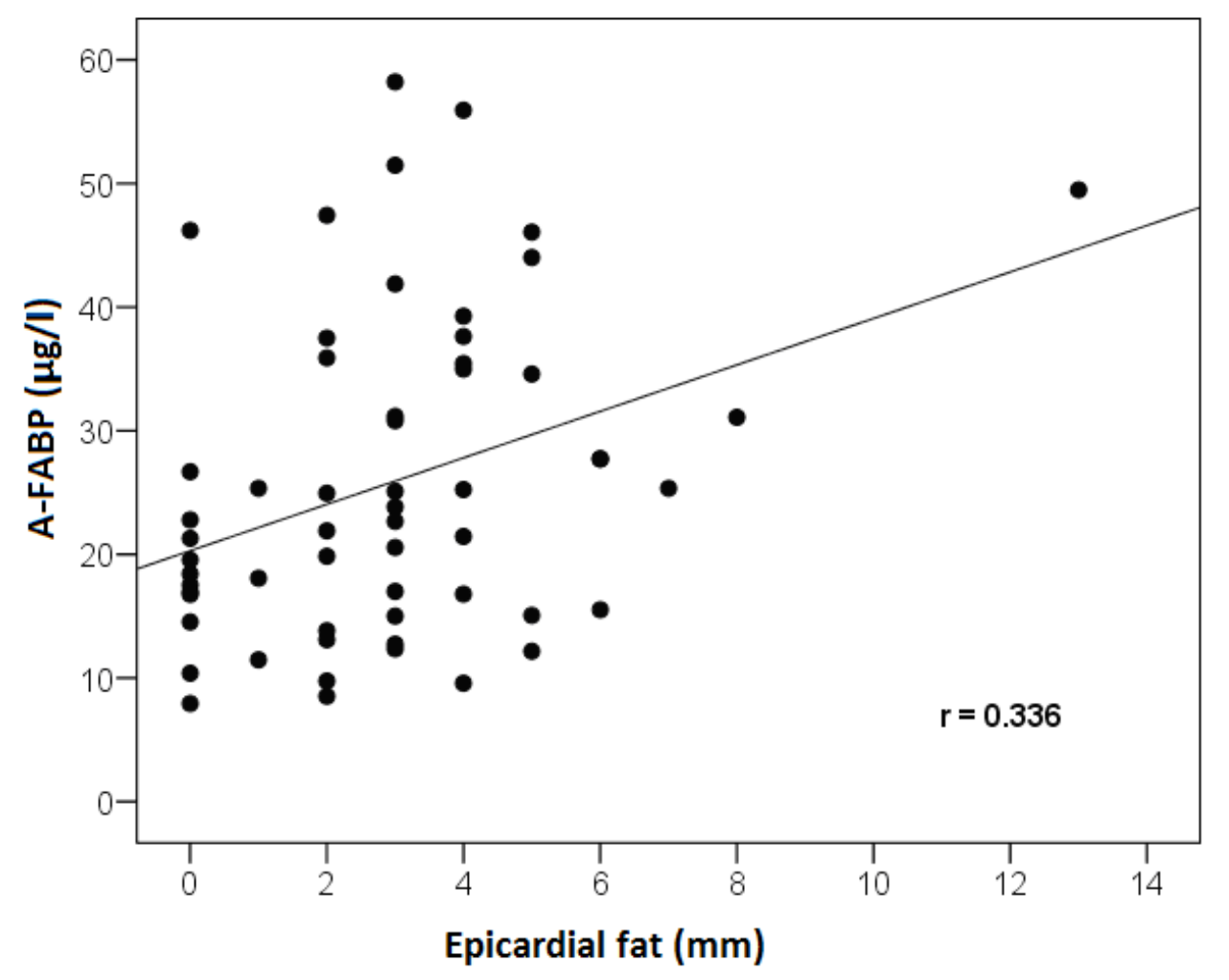

Fig. 1. Possitive correlation between amount of epicardial fat and A-FABP level was found. ( $r=0.336$; $P=0.010$ ). 
We have found a positive correlation between EPI and A-FABP in group of patients without ischemic heart disease $(\mathrm{r}=0.368 ; P=0.006)$.

We found a correlation between EPI and A-FABP $(\mathrm{r}=0.385 ; P=0.004)$ in non diabetic patients.

\section{DISCUSSION}

The growing understanding of the pathogenic role of ectopic fat is a topic of study. The group in the Framingham study ${ }^{18}$ showed that, in 3086 participants, visceral adipose tissue was associated with cardiovascular disease (hazard ratio 1.44 , CI 1.08-1.92; $P=0.01$ ) and cancer (hazard ratio 1.43 , CI 1.12-1.84; $P=0.005$ ). In a systematic review of 2012 (ref. $^{2}$ ) there was a positive correlation reported in most studies of relationship between EPI and CVD: the presence of EPI increased the risk of CVD. Studies of adipokines and EPI also exist. For example, Ogorodnikova et al showed that at-risk overweightobese women had significantly elevated epicardial fat and tested the lowest for adiponectin ${ }^{19}$. Other authors found a correlation between leptin levels and subcutaneous and visceral fat volume with controversial results ${ }^{20,21}$.

A-FABP is a promising marker connecting metabolic syndrome, inflammation and atherosclerosis, and recently long term studies ${ }^{22,23}$ have been published showing that persons with higher A-FABP levels have poor cardiovascular prognosis. Huang et al. ${ }^{24}$ published a study where they evaluated the association between serum adipocyte fatty acid-binding protein concentrations, left ventricular function and myocardial perfusion abnormalities in patients with coronary disease. They found an association between the A-FABP level, myocardial perfusion abnormalities and left ventricular function and predicted the presence of heart failure. Epicardial fat was not evaluated in their study.

Agra et al recently published an experimental study of gene expression of genes involved in adipogenesis including A-FABP in EPI and subcutaneous adipose tissue ${ }^{25}$. They found that epicardial adipocytes expressed significantly lower levels of adipogenic genes A-FABP than subcutaneous adipocytes. Upregulation of adipogenic genes was observed in obese patients. The enlargement of adipocyte size was related to A-FABP expression levels in stromal cells. This may show a new mechanism for understanding the relationship between EPI, obesity and CVD.

Our search through the available literature found only one study of correlation between A-FABP and EPI. Baessler et al. ${ }^{17}$ studied the association between A-FABP levels with left ventricular diastolic dysfunction (LVDD) in 50 morbidly obese subjects and compared them with 50 morbidly obese subjects without LVDD and control group of 24 heathy, lean subjects. A-FABP levels were significantly associated with LVDD and EPI. In our study we, too, found a correlation between A-FABP and EPI in overweight patients but did not find this in patients with normal BMI.

Interestingly, we found a correlation between A-FABP and EPI in asymptomatic relatives of patients with CVD with negative SPECT and coronarography results. It is probable that EPI together with higher A-FABP levels worsen prognoses by increasing metabolic and inflammatory risk factors. Chow et al. ${ }^{23}$ supported this suspicion in asymptomatic persons in whom they studied the influence of A-FABP levels on CVD prediction. However these authors did not study EPI, which could improve risk stratification.

We chose first degree relatives of patients with MI or stroke because family history is an established risk factor for myocardial infarction. Nielsen et al. ${ }^{26}$ found that in a Danish population, rate ratios calculated by Poisson models showed RR of 4.30 for siblings of patients with myocardial infarction, RR of 2.40 for children of maternal cases, and RR of 1.98 for children of paternal cases.

At this point in time, there are few studies which examined the influence of family history on risk factors of CVD linked with A-FABP.

Ota at $\mathrm{al}^{27}$ found that in a group of 30 normotensive patients, those with a positive family history of hypertension had higher levels of A-FABP than patients with negative family histories. The authors stated that it is unknown whether the correlation of elevated circulating A-FABP with insulin resistance and hypertension is a direct result of the physiological effects of A-FABP and that determination of serum A-FABP might be a novel approach for identifying individuals at risk for hypertension and atherosclerotic events.

Thus, there is need to follow up these asymptomatic persons and assess cardiovascular endpoints such as cardiac death and acute myocardial infarction.

The amount of EPI correlated with age, which is in concordance with previously published data by Guglielmi et al. ${ }^{28}$. A positive correlation between EPI and fibrinogen was published by Aydin et al. ${ }^{29}$.

We evaluated the calcium score. Correlation of this parameter with A-FABP level has been published ${ }^{15}$. The results of direct intervention on risk factors and its influence on A-FABP level have also been published ${ }^{16}$.

Limitations to this pilot study include small sample size, assessment of EPI by echocardiography and not by CT scan, but we judged the greater radiation burden in asymtpomatic people would be unethical, and a skilled echocardiographer is able to distiguish between epicardial fat and pericardial fluid. Also, we were not able to perform subanalyzes of possible sex differences because of sample size.

\section{CONCLUSION}

This is the first study to show a positive correlation between EPI and A-FABP in overweight patients with a family history of CVD. Because of possible clinical consequences there is a need for more studies.

\section{ABBREVIATIONS}

A-FABP, Adipocyte fatty acid binding protein; $\mathrm{CI}$, Confidence interval; $\mathrm{CRP}, \mathrm{C}$ reactive protein; $\mathrm{CV}$, 
Coefficient of variation; CVD, Cardiovascular disease; EPI, Epicardial fat; HDL, High density lipoprotein; FABP, Fatty acid binding protein; IL, Interleukin; LDL, Low density lipoprotein; Lp, Lipoprotein; mRNA, Messenger ribonucleic acid; SD, Standard deviation; TNF, Tumor necrosis factor.

Acknowledgement: Preparation of this manuscript has been supported by grant LF_2017_041.

Author contribution: All authors contributed in equal way in preparation of this manuscript.

Conflict of interest statement: None declared.

\section{REFERENCES}

1. Shimabukuro M, Kozuka C, Taira S, Yabiku K, Dagvasumberel M, Ishida M, Matsumoto S, Yagi S, Fukuda D, Yamakawa K, Higa M, Soeki T, Yoshida H, Masuzaki H, Sata M. Ectopic fat deposition and global cardiometabolic risk: new paradigm in cardiovascular medicine. Journal of Medical Investigation 2013;60(1-2):1-14.

2. Bertaso AG, Bertol D, Duncan BB, Foppa M. Epicardial fat: definition, measurements and systematic review of main outcomes. Arq Bras Cardiol 2013;101(1):18-28.

3. Cherian S, Lopaschuk GD, Carvalho E. Cellular cross- talk between epicardial adipose tissue and myocardium in relation to the pathogenesis of cardiovascular disease. Am J Physiol Endocrinol Metab 2012;303(8):937-49.

4. Rosito GA, Massaro JM, Hoffmann U, Ruberg FL, Mahabadi AA, Vasan RS, O'Donnell CJ, Fox CS. Pericardial fat,visceral abdominal fat, cardiovascular disease risk factors and vascular calcification in a community based sample: the Framingham Heart Study. Circulation 2008;117(5):605-13.

5. Ding J, Hsu FC, Harris TB, Liu Y, Kritchevsky SB, Szklo M, Ouyang P, Espeland MA, Lohman KK, Criqui MH, Allison M, Bluemke DA, Carr JJ. The association of pericardial fat with incident coronary heart disease. The Multiethnic Study of Atherosclerosis (MESA). Am J Clin Nutr 2009;90(3):499-504.

6. Storch J, Corsico B. The emerging functions and mechanisms of mammalian fatty acid-binding proteins. Annu Rev Nutr 2008;28(1):73-95.

7. Hsu BG, Chen YC, Lee RP, Lee CC, Lee CJ, Wang JH. Fasting serum level of fatty-acid- binding protein 4 positively correlates with metabolic syndrome in patients with coronary artery disease. Circ J 2010;74(2):327-31

8. Krusinova E, Pelikanova T. Fatty acid binding proteins in adipose tissue: A promising link between metabolic syndrome and atherosclerosis? Diabetes Research and Clinical Practice 2008;82(1):127-34.

9. Tso AW, Xu A, Sham PC, Wat NM, Wang Y, Fong $\mathrm{CH}$, Cheung BM, Janus ED, Lam KS. Serum adipocyte fatty acid-binding protein as a new biomarker predicting the development of type 2 diabetes: A 10-year prospective study in a Chinese cohort. Diabetes Care 2007;30(10):667-2672.

10. Makowski L, Boord JB, Maeda K, Babaev VR, Uysal KT, Morgan MA, Parker RA, Suttles J, Fazio S, Hotamisligil GS, Linton MF. Lack of macrophage fatty-acid-binding protein aP2 protects mice deficient in apolipoprotein E against atherosclerosis. Nat Med 2001;7(6):699705.

11. Miyoshi T, Onoue G, Hirohata A, Hirohata S, Usui S, Hina K, Kawamura H, Doi M, Kusano KF, Kusachi S, Ninomiya Y. Serum adipocyte fatty acid-binding protein is independently associated with coronary atherosclerotic burden measured by intravascular ultrasound. Atherosclerosis 2010;211(1):164-9.

12. Rhee EJ, Lee WY, Park CY, Oh KW, Kim BJ, Sung KC, Kim BS. The association of serum adipocyte fatty acid-binding protein with coronary artery disease in Korean adults. Eur J Endocrinol 2009;160(2):165-72.

13. Peeters W, de Kleijn DP, Vink A, van de Weg S, Schoneveld AH, Sze SK van der Spek PJ, de Vries JP, Moll FL, Pasterkamp G. Adipocyte fatty acid binding protein in atherosclerotic plaques is associated with local vulnerability and is predictive for the occurrence of adverse cardiovascular events. Eur Heart J 2011;32(14):1758-68.

14. Doi M, Miyoshi T, Hirohata S, Nakamura K, Usui S, Takeda K, Iwamoto M, Kusachi S, Kusano K, Ito H. Association of increased plasma adipocyte fatty acid-binding protein with coronary artery disease in non-elderly men. Cardiovasc Diabetol 2011;10(1):44.

15. Sovova E, Vrbkova J, Stejskal D, Kaletova M, Kaminek M, Metelkova I, Sova M, Benusova I, Doupalova P. Is there dependence between the level of AFABP and calcium score in asymptomatic relatives of patients with cardiovascular diseases? Vnitr Lék 2013;59(1):31-6.

16. Sovova E, Kaletova M, Stejskal D, Kaminek M, Budikova M, Metelkova I, Horakova D, Sova M, Sovova M, Palcik J, Zapletalova J. Intervention for cardiovascular risk factors decreases adipocyte fatty acid binding protein levels in males- a pilot study. Cent Eur J Med 2014;9(1):28-33.

17. Baessler A, Lamounier-Zepter $V$, Fenk S, Strack C, Lahmann C, Loew T, Schmitz G, Blüher M, Bornstein SR, Fischer M.Adipocyte fatty acidbinding protein levels are associated with left ventricular diastolic dysfunction in morbidly obese subjects. Nutr Diabetes 2014;4:106.

18. Britton KA, Massaro JM, Murabito JM, Kreger BE, Hoffmann U, Fox CS. Body fat distribution, incident cardiovascular disease, cancer, and all cause mortality. J Am Coll Cardiol 2013;62(10):921-5.

19. Ogorodnikova AD, Khan UI, McGinn AP, Zeb I, Budoff MJ, Harman SM, Miller VM, Brinton EA, Manson JE, Hodis HN, Merriam GR, Cedars MI, Taylor HS, Naftolin F, Lobo RA, Santoro N, Wildman RP. Ectopic fat and adipokines in metabolically benign overweight/obese women: The kronos early estrogen prevention study. Obesity 2013;21(8):1726-33.

20. Arnardottir ES, Maislin G, Jackson N, Schwab RJ, Benediktsdottir B Teff K, Juliusson S, Pack Al, Gislason T. The role of obesity, different fat compartments and sleep apnea severity in circulating leptin levels: The Icelandic Sleep Apnea Cohort Study. Int J Obes 2013;37(6):83542.

21. Tatsumi K, Kasahara Y, Kurosu K, Tanabe N, Takiguchi Y, Kuriyama T. Sleep oxygen desaturation and circulating leptin in obstructive sleep apnea- hypopnoea syndrome. Chest 2005;127(3):716-21.

22. von Eynatten $M$, Breitling LP, Roos $M$, Baumann $M$, Rothenbacher $D$, Brenner $\mathrm{H}$. Circulating adipocyte fatty acid binding protein levels and cardiovascular morbidity nad mortality in patients with coronary heart disease. A 10 year prospective study. Arterioscler Thromb Vasc Biol 2012;32(1):2327-35.

23. Chow WS, Tso AW, Xu A, Yuen MM, Fong CH, Lam TH, Lo SV, Tse HF Woo YC, Yeung CY, Cheung BM, Lam KS. Elevated circulating adipocyte fatty acid binding protein levels predict incident cardiovascular events in a community based cohort: A 12 year prospective study. J Am Heart Assoc 2013;2(1):1-8.

24. Huang CL, Wu YW, Wu CC, Lin L, Wu YC, Hsu PY, Jong YS, Yang WS. Association between serum adipocyte fatty- acid binding protein concentrations, left ventricular function and myocardial perfusion abnormalities in patients with coronary disease. Cardiovascular Diabetology 2013;12(1):105.

25. Agra RM, Fernández-Trasancos Á, Sierra J, González-Juanatey JR, Eiras S. Differential association of S100A9, an inflammatory marker and p53, a cell cycle marker, expression with epicardial adipocyte size in patients with cardiovascular dise ase. Inflammation 2014;37(5):150412.

26. Nielsen M, Andersson Ch, Gerds TA, Andersen PK, Jensen TB, Kober L, Gislason G, Torp-Pedersen Ch. Familial clustering of myocardial infarction in first-degree relatives: a nationwide study. Eur Heart J 2013;34:1198-203.

27. Ota H, Furuhashi M, Ishimura S, Koyama M, Okazaki Y, Mita T, Fuseya T, Yamashita T, Tanaka M, Yoshida H, Shimamoto K, Miura T. Elevation of fatty acid- binding protein 4 is predisposed by family history of hypertension and contributes to blood pressure elevation. Am J Hypertesion 2012;25:1124-30.

28. Guglielmi V, Maresca L, D'Adamo M, Di Roma M, Lanzillo C, Federici M, Lauro D, Preziosi P, Bellia A, Sbraccia P. Age related different relationships between ectopic adipose tissues and measures of central obesity in sedentary subjects. Plos One 2014;9(7):e103381.

29. Aydin H, Toprak A, Deyneli O, Yazici D, Tarçin O, Sancak S, Yavuz D, Akalin S. Epicardial fat tissue thicknes correlates with endothelial dysfunction and other cardiovascular risk factors in patients with metabolic syndrome. Metab Syndr Related Disord 2010;8(3):229-34. 